RESUMOS DE TESE/DISSERTAÇÃO'

APRENDER BRINCANDO: A PERCEPÇÃO DE ALUNOS ADOLESCENTES SOBRE GRUPOS DE ORIENTAÇÃO SEXUAL

\author{
LEARNING THROUGH PLAYING: THE PERCEPTION OF ADOLESCENT STUDENTS ABOUT \\ SEXUAL ORIENTATION GROUPS
}

\author{
APRENDER A JUGAR: LA PERCEPCIÓN DE LOS ALUMNOS ADOLESCENTES SOBRE \\ GRUPOS DE ORIENTACIÓN SEXUAL
}

Autora: Marta Angélica lossi

Orientadora: Maria Aparecida Tedeschi Cano

\begin{abstract}
RESUMO: Considerando o exercício da nossa prática, e a importância que a adolescência e a orientação sexual assumiram nos últimos anos, é que buscamos realizar o presente estudo. Nosso objetivo foi conhecer a percepção de alunos que haviam participado de um grupo de adolescentes com relação à dinâmica desses grupos e à orientação sexual, tendo como referencial teórico os aspectos conceituais da adolescência, sexualidade na adolescência, vulnerabilidade, orientação sexual, metodologia participativa e lúdica. Buscamos na abordagem qualitativa, uma alternativa metodológica para entender a realidade expressa através das percepções desses adolescentes. Do ponto de vista teórico e formal, optamos pela modalidade de Pesquisa Estratégica. Realizamos o estudo em uma escola municipal de Ribeirão Preto, tendo como atores sociais, alunos que participaram de grupos de orientação nas $4^{a}$ séries. Com relação ao processo de trabalho de campo, para coleta de dados, utilizamos a técnica da entrevista semi-estruturada, tendo como técnica complementar a realização de grupos focais. O tratamento e análise dos dados foram feitos através da análise de conteúdo, elaborada por Bardin. A partir das falas dos atores sociais, pudemos identificar núcleos temáticos, relacionados ao lúdico, enquanto processo facilitador para a aquisição do conhecimento e reflexão; ao conteúdo abordado e a participação nos grupos, enquanto fator determinante para o seu futuro e um caminho para o diálogo intra familiar.
\end{abstract}

\title{
CUIDADO CULTURAL COMPARTILHADO EM GRUPO COM PESSOAS NA CONDIÇÃO CRÔNICA DE DIABETES MELLITUS
}

\author{
CULTURAL CARE SHARED BY PATIENTS SUFFERING FROM CHRONIC MELLITUS DIABETES \\ CUIDADO CULTURAL COMPARTIDO EN GRUPO CON PERSONAS EN CONDICIONES \\ CRÓNICAS DE DIABETES MELLITUS
}

Autora: Vilma Beltrame Orientadora: Mercedes Trentini

RESUMO: o presente trabalho intitulado O Cuidado Cultural Compartilhado em Grupo com Pessoas na Condição Crônica de Diabetes Mellitus, trata-se de uma pesquisa convergente assistencial que teve como objetivo conduzir um processo de reflexão sobre o cuidado com um grupo de pessoas com Diabetes Mellitus baseado na Teoria da Diversidade e Universalidade do cuidado cultural de LEININGER e no Processo dos Quatro Erres - 4Rs - de TRENTINI e DIAS. O mesmo se deu em uma Associação de Diabéticos, com um grupo de doze clientes e dois profissionais durante o período de setembro de 1999 a março de 2000. Ao todo foram dezoito encontros, totalizando 36 horas de convivência. O marco conceptual fundamentouse em minhas crenças e em alguns pressupostos de Leininger e também em seus conceitos de cultura, cuidado, ser humano, saúde, enfermagem e ambiente. O processo de formação do grupo - 4Rs - com suas fases de reconhecimento, revelação, repartir e repensar permitiu a coleta de dados para conhecer a realidade de vida do grupo, facilitou a assistência

${ }^{1}$ Cópia das teses/dissertações solicitar informações pelo E-mail cepen@abennacional.org.br 
de enfermagem, de uma forma coerente, sem imposição cultural, fazendo com que o grupo planejasse, executasse e avaliasse a prática do cuidado. Os dados obtidos foram analisados seguindo o modelo do sol nascente. Seu uso é coerente e proporciona uma visão completa do mundo do cliente. O conhecimento das dimensões da estrutura social e cultural deuse através do conhecimento das várias estruturas que compõem essas dimensões. Durante a caminhada, o grupo falou sobre os fatores tecnológico, educacional, político e legal, religioso e filosófico, familiar e social, expressou seus valores culturais e estilo de vida, proporcionando condições para se compreender os padrões e expressões de cuidados e ao mesmo tempo identificar quais as práticas que poderiam ser mantidas, negociadas e repadronizadas, para que se efetivasse o cuidado de enfermagem culturalmente coerente. A aplicação dessa metodologia é possível, efetiva e gratificante, mas o profissional que deseja implementá-la terá que inicialmente repadronizar seus valores, reconhecer o grupo como um instrumento de cuidado, dentro de uma nova perspectiva, onde não há quem só cuide ou quem só é cuidado.

\title{
ENCONTROS E DESENCONTROS NA EXISTÊNCIA DAS MULHERES DURANTE O CLIMATÉRIO
}

\author{
WOMEN EXPERIENCING MENOPAUSE \\ ENCUENTROS Y DESENCUENTROS EN LA EXISTENCIA DE LAS MUJERES DURANTE EL \\ CLIMATERIO
}

Autora: Ivete Ghinato Dauod Orientadora: Maria da Glória Santana

RESUMO: Este estudo registra a minha inquietude ao percorrer novos caminhos na Enfermagem, refletindo os anseios da Mulher/Enfermeira, que vivencia o período do climatério. Trata-se de um trabalho realizado com um grupo de mulheres, durante o seu climatério, objetivando conhecer e compreender o seu pensamento com relação a essa etapa de suas vidas. Mediante a construção de um processo educativo embasado na minha experiência profissional, em alguns princípios da teoria Transcultural de Leininger, somados à teoria da problematização de Bordenave. Este estudo, de abordagem qualitativa, foi desenvolvido no Hospital Universitário $(\mathrm{HU})$, de Rio Grande. Os dados foram coletados em sete encontros com um grupo de mulheres, trabalhadoras ou não do HU, que espontaneamente optaram em participar da pesquisa. A depressão e a terapia de reposição hormonal surgiram como pontos chaves para a discussão do grupo e, a partir daí, delinearam-se os demais temas discutidos, que foram permeados pela ação do cuidado cultural, chegando-se na experiência das mulheres quanto a sua assistência à saúde no HU. As mulheres se reconhecem como sós, não encontrando a sintonia com a família e o companheiro; induzidas pela família a procurar auxílio para os seus anseios e angústias no âmbito profissional, não encontrando o que necessitam. As mulheres, apontam o processo educativo, onde o cuidar é fundamentado na interação entre a Enfermeira e a Mulher, como sendo um espaço naquela realidade, onde elas encontrariam a assistência necessária e desejada. A assistência de enfermagem à mulher durante o climatério requer um olhar a partir desta mulher, possibilitando assim o planejamento das ações do cuidado culturalmente congruente. A Enfermagem necessita rever a sua prática de assistência a essa mulher, enfocando-a como usuária do Sistema Único de Saúde, uma vez que a categoria ainda está voltada a atendê-la, principalmente, no seu período reprodutivo.

\section{GRUPOS DE CONVIVÊNCIA: DO MITO À REALIDADE NO CUIDADO DO CARDIOPATA}

\author{
COMPANIONSHIP GROUPS: FROM MYTH TO REALITY IN CARING FOR THE CARDIAC PATIENT
}

\section{GRUPOS DE CONVIVENCIA: DEL MITO A LA REALIDAD EN EL CUIDADO DEL CARDIOPATA}

Autora: Andréia Bendine Gastaldi Orientadora: Ymiracy N. de Souza Polak

RESUMO: Este estudo é o relato de uma prática assistencial desenvolvida junto a um grupo de cardiopatas que teve como objetivos: desenvolver uma prática de cuidado com cardiopatas, num grupo de convivência, alicerçado na concepção de 